\title{
Experience Trailers
}

Michael Twidale, University of Illinois at Urbana-Champaign

Stefan Rennick-Egglestone, University of Nottingham

We live in a world flooded with digital services, digital media, and leisure experiences. For a consumer, this means that choosing how to commit scarce time and financial resources can be a challenge. For a producer, it raises questions of how to persuade people to try out, adopt, or purchase their offering-especially if it is sufficiently novel that potential consumers might fail to understand what it is or why they might want to engage with it. Sometimes describing in words what a new thing does is not enough. People want to know what it will feel like.

Though we might think of informing the selection process as "just" a marketing problem, in reality potential users are likely to be engaging with a range of complex questions as part of their decisionmaking process, which makes this a topic of interest to both user experience designers and $\mathrm{HCl}$ researchers. These questions include: What is it for? Why yours rather than theirs? What will using it feel like? and Why should I trust your offering? Navigating these considerations can be expensiveboth financially and temporally - and a thorough investigation of all options may be infeasible in many cases. In this context, potential users may use heuristics to help them make reasonable choices.

In this article, we consider a class of existing artifacts or user experiences that we have grouped together and called experience trailers. We define an experience trailer as something that helps a person understand what it will feel like to engage with a current or future user experience. The term alludes to film trailers, which do the same job in helping people decide whether to watch a particular film. The design of experience trailers frequently draws on approaches developed during more than a century of film-trailer production work, but the broader range of artifacts that they are used to promote has led to innovation in production and delivery. This has arguably created a new genre, worthy of study in its own right. We discuss a small selection of examples to showcase approaches that user experience designers have taken.

\section{Experience Trailers in the Gaming Industry}

Ever a driver of innovation, the gaming industry has been an enthusiastic producer of experience trailers to promote games. An early example, produced for the Nintendo Wii, is a linear video that cuts backwards and forwards between in-game footage and footage of family members communally playing the game (https://www.youtube.com/watch?v=mCufArSg-SQ ). The outcome is that the viewer can see how a novel (at the time) and hence unfamiliar piece of technology enables particularly social and informal kinds of game-playing, unlike many people's experience or expectations of computer gaming.

A similar approach can be seen in a trailer for the Kinect

https://www.youtube.com/watch?v=XJNjTyBr1Hg ), which starts with shots of facial expressions, with hints that these will be important to the interaction. It then shifts to a child interacting with a game, with their family sitting on a sofa. Showing the context of use is a common approach in experience trailer design, useful in helping a viewer quickly grasp what a piece of technology will look like, where it might be used, and how it might fit into their lives. This is one way in which 
experience trailers differ from film trailers: The latter typically use only footage taken directly from the film being promoted.

Though experience trailers might help a consumer navigate a selection process, they should also be understood as promotional products, with the power to distort selection. Interesting examples of this have been documented in so-called cinematic games trailers, where the game engine itself is used to produce a video narrative composed of in-game footage, typically illustrating the graphical complexity of the game and providing insights into its narrative arc.

Some cinematic trailers use shots hinting at interaction that are not present in the game, hence offering a misleading view of what it will feel like to play it-for example, moving cameras that swoop through a battle scene [1]. Production difficulties can also mean that the graphical or interactional complexity of the final product does not match that of the trailer [2]. Deception has also been documented in film-trailer production, for example through inclusion of shots that do not make the final cut and hence distort a viewer's understanding of the film [3].

\section{Experience Trailers for Wearable Medical Devices}

While the choice to engage in a game might require an investment of well under a hundred dollars and lead to hundreds of hours of use, the choice to integrate a wearable medical device into everyday life might cost hundreds or even thousands of dollars, and involve a rapid (and emotionally laden) transition to permanent device usage. For reasons like this, medical-device companies have been experimenting with experience trailers. One example is an animated video (Figure 1, left) presenting key elements of the user experience of an advanced insulin pump (https://www.youtube.com/watch?v=ASQo9bIPch4), including:

- options for where the device can be worn on the body,

- the interactive interface of a connected unit,

- visualizations produced by this unit, and

- the functionality of the device in an emergency (such as hypoglycemia).

What makes this an experience trailer, rather than a training video, is that these elements are presented rapidly, with insufficient time to absorb what is shown. The intention is that the user gains a general understanding of what it would feel like to use the device, rather than a precise understanding of the mechanics of use. We have observed this fly-through style in experience trailers for a range of complex products where a user needs to obtain a rapid overview of functionality so as to make a choice, such as complex design software (Figure 1, right) (https://www.youtube.com/watch?v=aXfnGyliTDM).
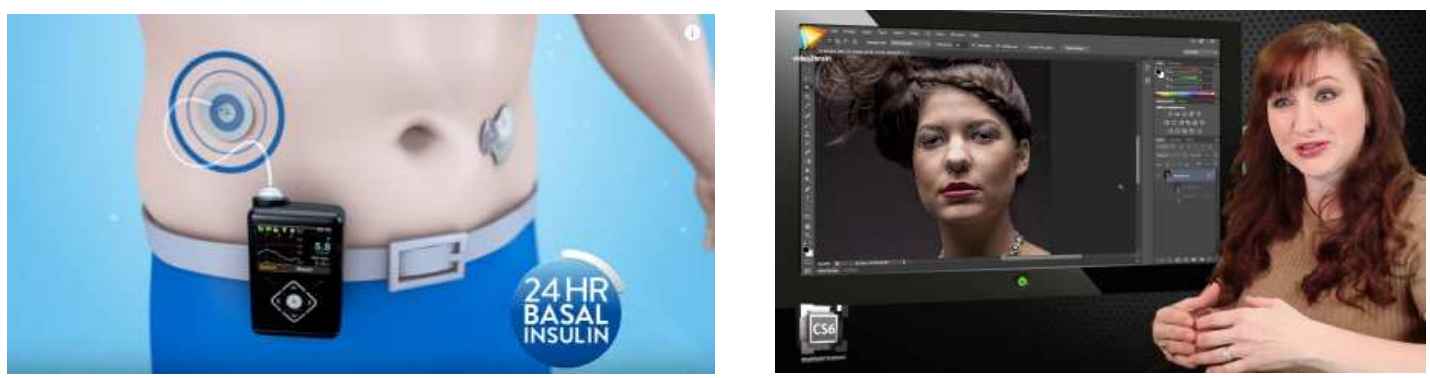

Figure 1. Experience trailer for an insulin pump (left) and design software offering (right). 


\section{Experience Trailers for Novel Interactive Experiences}

We first became sensitized to experience trailers in the context of research into the design of novel user experiences. To evaluate these experiences, we need people to test them out for us. But how can we effectively recruit people to test something that they don't know about, particularly if they worry about being embarrassed or scared by taking part? The ethical principle of informed consent is critically important but raises a question of how to truly inform people about a new and strange experience. Experience trailers might help participants understand what they are getting themselves into. An artefact which might inform the design of experience trailers for novel experiences is Breathless [4], illustrated in Figure 2. Breathless was a large swing, controlled by the rhythm of a participant's breathing, as captured by an instrumented gas mask. Movement through Breathless was choreographed by event staff:

Stage 1: Participants line up, then arrive at a desk where they are fitted with a mask.

Stage 2: The mask's breathing sensor is activated, and the participant's breathing is shown on a projection screen.

Stage 3: The participant sits and observes the operation of the swing, at this point controlled by the breathing of the participant riding it.

Stage 4: The participant is assisted in mounting the swing (Figure 2, left), and its movements are controlled by the participant who has just vacated it (Figure 2, right).

Stage 5: Control switches to the participant riding the swing.

Stage 6: The participant in the cradle dismounts, takes the vacant position in the seat, and controls the next rider.

Here, stages 2, 3, and 4 were designed to serve as a trailer for the novel interaction between breathing and swing, intentionally supporting the user in having a satisfying experience in stages 5 and 6.

A second example of a novel interactive experience incorporating a "live" trailer is Fairground: Thrill Laboratory [5]. Here, video and biodata captured on a fairground ride were presented to a live audience, and were used to inform and entertain, but also served a function of encouraging them to volunteer as a future ride participant. 

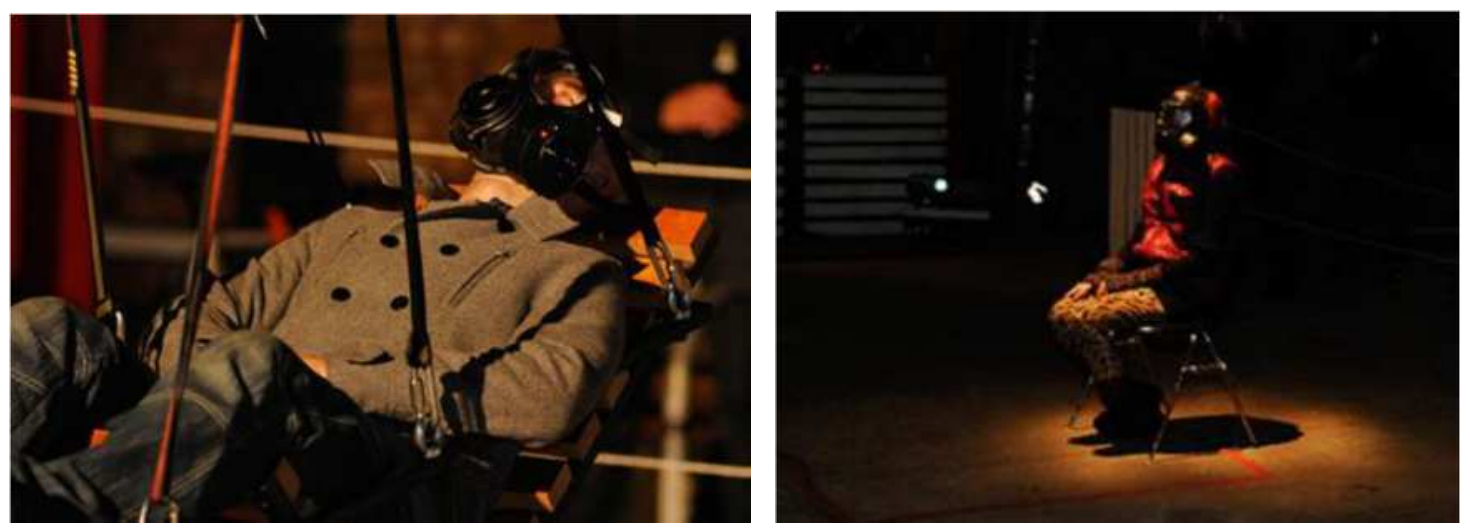

Figure 2. Breathless. Left, riding. Right, controlling. Image courtesy Brendan Walker.

\section{Design Considerations Around Experience Trailers}

We have drawn on a select sample of experience trailers to elucidate the concept. These examples can help us see some of the design challenges and purposes behind experience trailers. An experience trailer has much in common with a film trailer. A film trailer tries to persuade a viewer why one film is worth a person's scarce time and money, versus some other film or other kind of entertainment. That is done by helping the viewer get a sense of what the film is about, but also what viewing the film will feel like. Genre is important here-letting people know whether a film is a comedy, a musical, a thriller, or horror. Genre creates expectations of what watching will be like so you can decide if you are in the mood for that particular kind of experience. It is possible to break the rules of a genre, but if a film does that, it may help to warn people in the trailer-otherwise they may get annoyed and feel misled.

Some genres explicitly point to the kind of experience that you might expect, such as thriller, mystery, documentary, horror, or comedy. However, although genre can be useful in helping a person decide to watch a particular film, it may not be sufficient. Take two famous films: Cabaret and The Sound of Music. Both are indisputably musicals. Both have a similar cultural-historical setting (the rise of Nazi power in central Europe). Someone who was provided only with that information may love one and loathe the other-or may enjoy both, but in very different ways. Trailers can evoke the very different feel of the two films, and hence enable a reasoned choice between them.

Various techniques are used in the design of film trailers that we see in experience trailers. These include:

- Careful selection of key episodes, particularly those that make the film noteworthy

- Some sense of the story arc, so a viewer can get a gist of the kind of story involved

- A voiceover to help give an overview, explaining what is going on given the necessarily abbreviated nature of what can be seen

- Critical reviews, often comparing it favorably with other films that are similar in some way.

Film trailers may not want to give too much away, especially plot spoilers. This issue may seem less relevant to experience trailers, but for example when running a usability evaluation, we may not want to give the whole game away. So, similar to a film trailer, we may sketch out the generalities of the experience while not revealing all the details. 
Experience trailers have to answer similar questions (What is it about? What is it like?) but with a greater emphasis on the question of what engaging with this product or activity will feel like. Particular challenges arise when the intended experience is somewhat different from possible expectations, or a genre where a person might think the artifact belongs. It can be particularly difficult if the product or service is intended to be radically different from its competitors.

The advertisement for the Wii is a particularly good example of that. At the time, computer games were regarded as a niche activity, often seen as violent and of greater appeal to younger people, particularly young men. They raised connotations of playing alone or with like-minded friends in a basement or dorm room, as a somewhat exclusionary activity that required considerable focus and expertise to enjoy.

The Wii was a novel product with a novel input device associated with a set of games, many of which were more casual in style and intended to be enjoyed by families, often across wide ranges of ability. The design of the device and some of the associated games facilitated that, but the trailer needed to explain to people that playing with the Wii was a rather different kind of experience than perhaps people associated with computer games. To do that, it was important to show the wider contextnot just what you would see on the screen, but the wider activity in the living room. That included showing the interaction with the Wii controller, showing its novelty and also implying it was easy for non-gamers to learn how to use.

Like many other game trailers, it of course showed the players having fun. But it also showed a wider context of a larger family group enjoying the activity-even if they were not currently playing. The Wii facilitated not just play but also playful social watching, commentating, cheering, and discussing; the trailer emphasized an experience that transcended simple game playing.

Similar challenges occur with other new technologies, where it is important to help people understand what this new experience will actually be like-and why it is different from (and hopefully better than) other experiences, as well as their expectations.

\section{Conclusions and Future Opportunities}

Experience trailers can be used like film trailers: to help people decide which of many competing claims on their time and money to choose. With interactive software and devices, a static description or list of features is frequently insufficient for a well-informed choice. Even a simple demo may not be enough; people may reasonably want to know what it will feel like to actually use the product-before even trying it. Just as a film trailer does not try to be a précis of a film, an experience trailer does not have to convey the entire experience; a flavor of the experience may be very useful. This is particularly challenging-and important-when the experience of using the technology is novel, or substantially unlike what a person might imagine from their prior experience.

In describing experience trailers, we do not claim to have invented a new way of interacting or a new subgenre of demo or video. Some people are already doing this, and some pioneers did it decades ago. We think it is useful to note the problems of imagining oneself using a novel technology that 
experience trailers try to address, and to be aware of some of the techniques used. Several of our examples are video experience trailers, but a few use live action and participation as a kind of trailer. We hope that others will continue to expand both the techniques and the use contexts of experience trailers.

We think an especially important use is in providing better informed consent for volunteers taking part in research studies with novel software. We are strong advocates of more, earlier, and more frequent user testing, and so it is important to ensure that these can be undertaken quickly, easily, ethically, and with minimal burdens on both researchers and testers.

For particularly novel software, including some developed by researchers as radical proofs of concept, the issue becomes even more acute. In some cases, this can be explained textually, often by analogy, such as "It's like sending text messages, but to loads of people all at once." In other cases, we may be tempted to say, "Just try it-trust me." However, an unconvinced potential user may reasonably require a bit more information about the user experience before committing themselves. This is where an experience trailer can be useful.

\section{Acknowledgements}

This work has been supported by the Mixed Reality Laboratory "Living with Digital Ubiquity" platform grant (UK EPSRC EP/M000877/1).

\section{Endnotes}

1. Parker, L. The problem with game trailers. Gamespot. Mar. 12, 2012; http://www.gamespot.com/articles/the-problem-with-game-trailers/1100-6365663/

2. Duwell, R. Graphical downgrades stirring up controversy in gaming. Techbuffalo. Mar. 24, 2014; http://www.technobuffalo.com/2014/03/24/graphical-downgrades-stirring-up-controversy-ingaming/

3. Kernan, L. Coming Attractions: Reading American Movie Trailers. Univ. of Texas Press, Austin, 2004.

4. Rennick Egglestone, S., Walker, B., Marshall, J., and Benford, S. Analysing the playground: Sensitizing concepts to inform systems that promote playful interaction. Proc. of Interact 2011.

5. Schnädelbach, H., Rennick Egglestone, S., Reeves, S., Benford, S., and Walker, B. Performing Thrill: Designing telemetry systems and spectator interfaces for amusement rides. Proc. of CHI 2008.

Michael Twidale does research in computer-supported cooperative work, computer-supported collaborative learning, and human-computer interaction, with a particular interest in informal social learning of technology.twidale@illinois.edu

Stefan Rennick-Egglestone is a design researcher with interests in digital healthcare interventions and the integration of technology into creative practice and performance. He currently works in the Nottingham Institute of Mental Health. stefan.egglestone@nottingham.ac.uk

\section{Insights}

- Experience trailers can help potential users understand what using a novel piece of software will feel like.

- They are similar to film trailers but convey a sense of the user experience. 
- They are especially important when the experience of an application is novel or not what a person might expect. 